\title{
Centrais Fotovoltaicas para a Microprodução
}

\section{Enquadramento}

Portugal, produz apenas uma pequena parte da energia que consome, toda a restante energia consumida é importada.

Portugal apresenta uma forte dependência energética do exterior, das maiores da UE.

Não explorando quaisquer recursos energéticos fósseis no seu território desde 1995 (quando deixou de extrair carvão), a sua própria produção de energia assenta exclusivamente no aproveitamento dos recursos renováveis, como sendo a água, o vento, a biomassa e outros em menor escala.

Esta situação tem consequências directas na nossa economia, uma vez que o custo dos combustíveis fósseis importados encarece a produção de bens e serviços em território nacional. Para além disso tem também implicações sociais, pois representa custos acrescidos para o consumidor e reflecte-se no ambiente, devido à produção crescente de Gases com Efeito de Estufa (GEE).

No ano de 2008 a potência instalada em Portugal era de 14916 MW, sendo que 30,7\% dessa potência é da responsabilidade das centrais hidroeléctricas, $39,01 \%$ da responsabilidade de centrais termoeléctricas e 30,29\% é referente a produção em regime especial (P.R.E.). De entre os P.R.E. destacam-se os $2624 \mathrm{MW}$ da responsabilidade de produtores eólicos e apenas $50 \mathrm{MW}$ instalados em sistemas fotovoltaicos [1].

No entanto Portugal, à excepção do Chipre, tem a melhor insolação anual de toda a Europa, com valores $70 \%$ superiores aos verificados na Alemanha. Esta diferença leva a que o custo da electricidade produzida em condições idênticas seja $40 \%$ menor em Portugal. Este aspecto é uma enorme vantagem que tem de ser capitalizada.

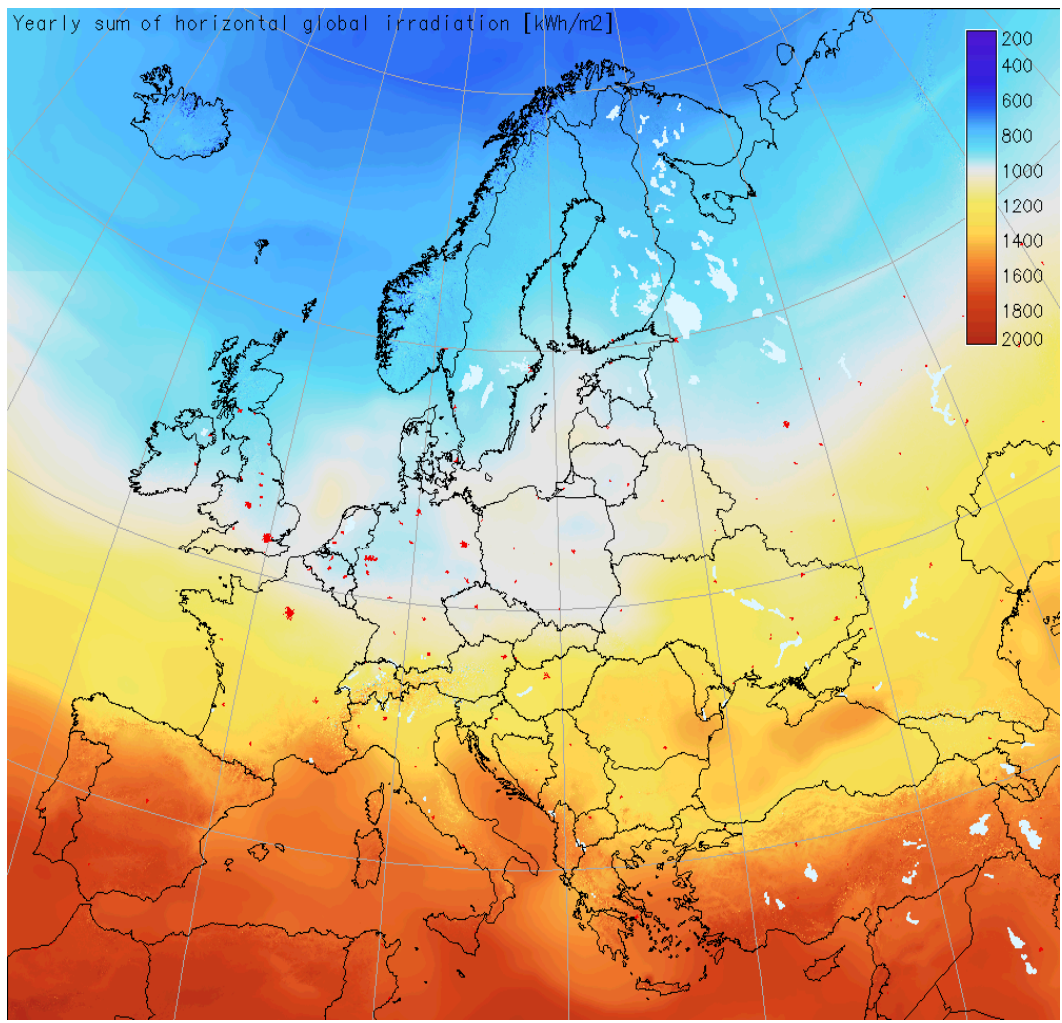

Fig.1 Irradiação solar (kWh/m2) 


\section{Produção Descentralizada}

Em Portugal, a produção de energia eléctrica através de instalações de pequena escala, utilizando fontes renováveis de energia ou processos de conversão de elevada eficiência energética, pode contribuir para uma alteração do panorama energético português, de forte dependência do exterior.

Com a entrada em vigor do Decreto-Lei no 363/2007 de 2 de Novembro, cujo objecto é o de estabelecer o regime jurídico aplicável à produção de electricidade por unidades de microprodução, a produção descentralizada, nomeadamente a produção através de centrais fotovoltaicas, atingiu uma grande dinâmica.

Com a produção mais próxima dos locais de consumo energético consegue reduzir-se os custos de transporte e distribuição, permitindo a autonomia e redundância energética.

Com a ligação destes equipamentos de produção às redes de baixa tensão, o paradigma do sistema energético muda.

As redes de baixa tensão passam a assumir um protagonismo cada vez maior em termos da obtenção de uma maior eficiência económica e energética.

A nível mundial também há a preocupação da produção descentralizada, salientando-se a Alemanha que foi um dos países pioneiros na utilização da energia fotovoltaica distribuída.
Entre 1990 e 1995 promoveu um programa de instalação de painéis fotovoltaicos ligados à rede em 1.000 telhados, vindo a atingir a marca de 2.250 equipamentos, com potência média de 2,6 kWp por telhado, abrangendo mais de 40 cidades. Este projecto foi um sucesso, o que deu origem a um novo programa. O "100.000 telhados solares" foi lançado, com o objectivo de alcançar $500 \mathrm{MW}$ de geração de energia solar [2]. No final de 2008 a Alemanha tinha mais de $5 G W$ de potência instalada de origem fotovoltaica, apresentando taxas de crescimento de 1,5 GW/ano.

\section{Componentes de uma Central Fotovoltaica}

Como o dimensionamento de centrais de microprodução fotovoltaicas é um assunto ainda novo mas em rápida evolução, nomeadamente em termos de necessidade de instalação, a formação de todos os agentes envolvidos no processo é ainda uma lacuna.

É normal verem-se cometidos alguns erros de dimensionamento, instalação e operação dos sistemas.

Aspectos como a localização, a escolha do inversor, a escolha do tipo de painel fotovoltaico a instalar, o estudo da estrutura de suporte, a análise da potência à entrada (DC) e a injectar (AC) e a simulação do sistema antes da instalação são muitas vezes descurados pelos técnicos e projectistas, mas que assumem uma importância extrema para que o sistema escolhido funcione nas condições óptimas.

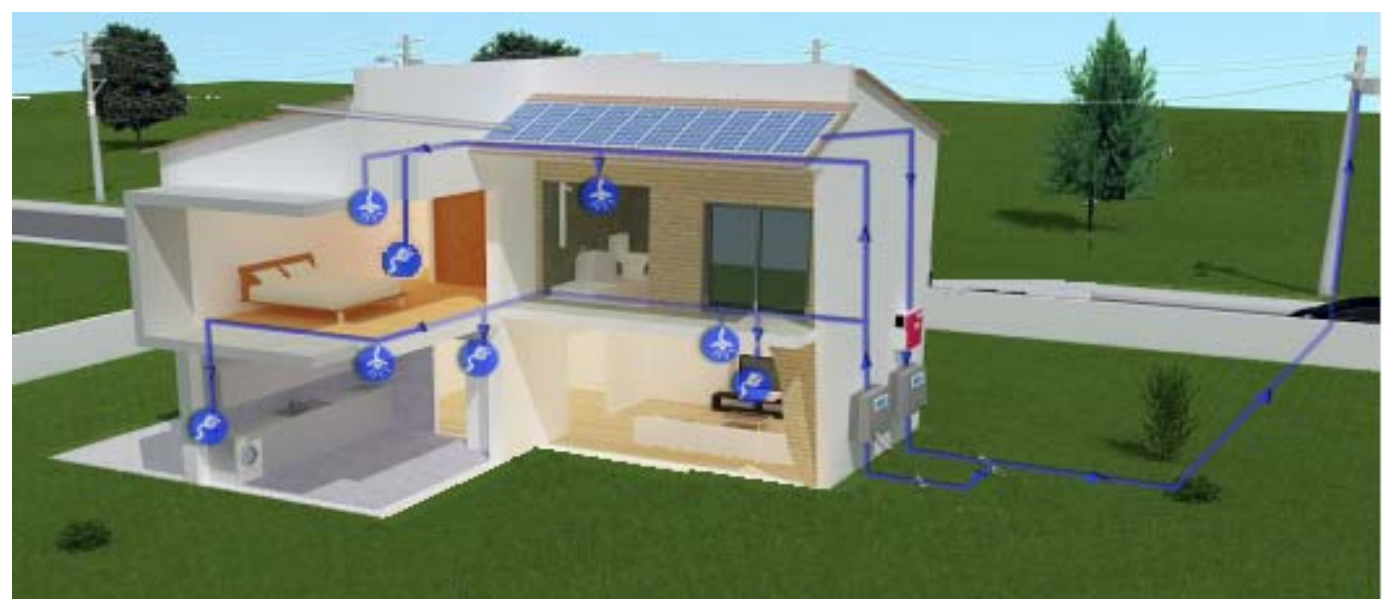

Fig.2 Microprodução descentralizada 


\section{ARTIGO TÉCNICO}

\section{a) Localização}

O sistema fotovoltaico pode ser instalado em qualquer superfície com boa exposição solar.

Para optimizar o rendimento do sistema fotovoltaico, este é adaptado às características arquitectónicas do edifício, podendo ser instalado em telhados inclinados ou planos, integrados nas fachadas ou em campo aberto. A orientação dos painéis também é um aspecto muito importante. Como Portugal está situado no hemisfério Norte a orientação ideal é voltada para sul.

A localização da instalação é muito importante para se poder realizar um projecto mais coerente e real. Cada local tem uma incidência do sol distinta, alterando assim a produção de energia eléctrica.

O estudo realizado na Alemanha, no Institut für Solare Energiesysteme (ISE), em Fraunhofer [3] consegue dar uma perfeita noção da variação da radiação solar com o ângulo de inclinação e a sua orientação (figura 3). De salientar que o referido instituto trabalha no estudo de sistemas fotovoltaicos há mais de 20 anos.

A radiação tem o seu ponto máximo de incidência quando orientado a Sul com uma inclinação de $30^{\circ}$, mas consegue-se ter praticamente a mesma radiação com variações de ângulo de inclinação entre aproximadamente os $17^{\circ}$ e os $43^{\circ}$, bem como um ângulo azimutal, isto é, ângulo formado entre a

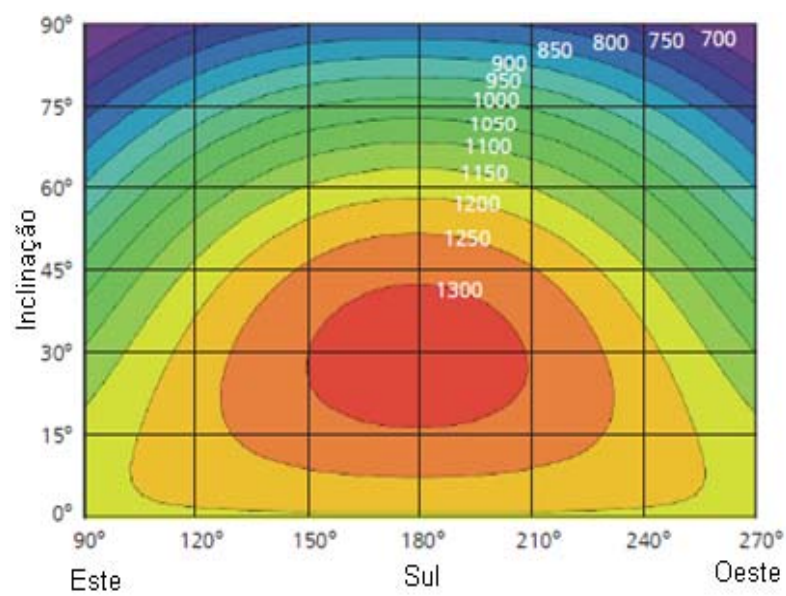

Fig. 3 - Variação da Radiação solar kWh/m2 direcção do Sul e a projecção da linha do sol, próximo do intervalo compreendido entre $150^{\circ}$ Este e $208^{\circ}$ Oeste.

O mesmo se passa se em vez de se analisar a radiação, se analisar a energia recebida. É facilmente perceptível pela figura 4 que o ponto de orientação em que a energia recebida é maior é com uma inclinação de $30^{\circ}$ e orientada a Sul. No entanto é possível com uma inclinação e orientação diferentes obter a mesma energia.

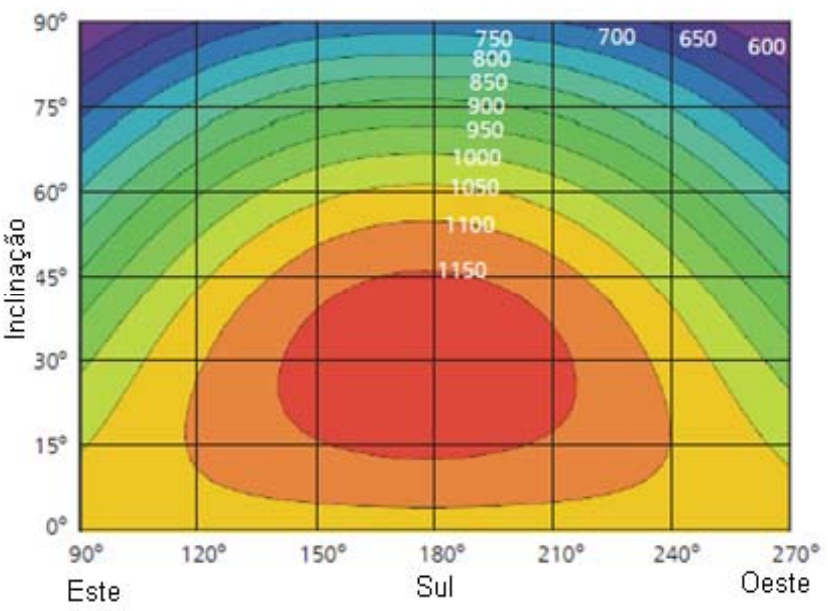

Fig. 4- Variação da energia produzida.

\section{b) Inversor}

Nos sistemas conectados à rede, a corrente DC produzida pelos painéis fotovoltaicos não pode ser ligada directamente à rede eléctrica.

Para tal existem equipamentos, denominados por inversores, que fazem a conversão de corrente contínua em corrente alternada, com características similares à da rede eléctrica, no que diz respeito à tensão, frequência, forma de onda, distorção harmónica, etc.

Os inversores, como qualquer outro componente de um sistema fotovoltaico, devem dissipar o mínimo de potência, produzir uma tensão com uma taxa de distorção harmónica baixa e em sincronismo com a rede eléctrica, quando o sistema estiver conectado à rede. 
No caso de inversores conectados à rede eléctrica, estes podem ser classificados em dois tipos, os que são comutados pela própria rede, que utilizam o sinal da mesma para se sincronizarem e os auto-comutados, onde um circuito electrónico no inversor controla e sincroniza o sinal ao sinal da rede.

Um dos critérios mais importantes na escolha do inversor é o seu rendimento. Sendo este o elemento que converte a energia continua vinda dos painéis fotovoltaicos em energia alternada, quanto maior for o seu rendimento menores serão as perdas da conversão.

Algumas marcas desenvolveram inversores específicos para serem usados em Portugal, no entanto deverá ser escolhido um inversor com um rendimento superior a 95\%, com invólucro resistente (aconselhável IP 65) e com um bom sistema de refrigeração.

O site www.renovaveisnahora.pt disponibiliza uma lista de inversores que se encontram certificados em Portugal. 0 produtor pode instalar um outro inversor, mas a certificação da instalação ficará pendente até ser apresentado o certificado de conformidade do equipamento.

Existem vários aspectos condicionantes da escolha dos inversores, mas no caso da microgeração um dos maiores factores que limitam a escolha dos inversores e o rendimento do sistema são as perdas por "mismatch". A tensão DC máxima permitida à entrada do inversor, a corrente máxima, o número de seguidores MPP e o número máximo de "strings" permitidas pelo inversor, importante para limitar a influência das perdas por mismatch, são também dados que assumem elevada importância aquando da selecção do inversor a aplicar na instalação.

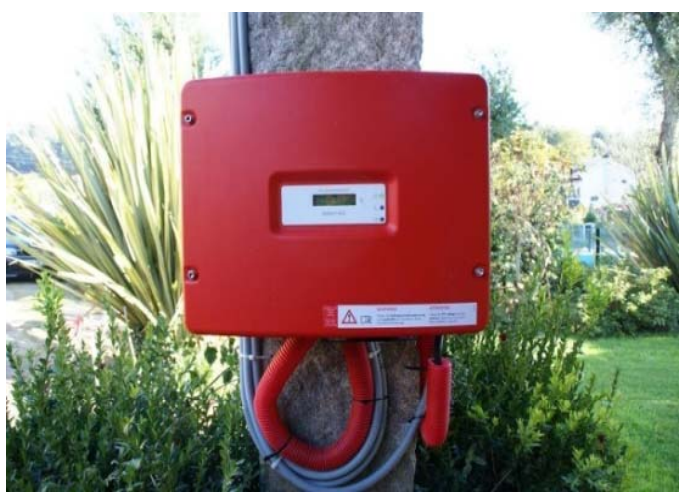

Fig. 5- Inversor de rede

\section{c) Painel Fotovoltaico}

A escolha dos painéis fotovoltaicos a instalar deve atender a vários factores, o primeiro deles é o custo por Wp.

Com a elevada concorrência que existe hoje em dia no mercado, uma análise atenta aos painéis disponíveis poderá trazer alguns ganhos nos custos de aquisição. No entanto, factores como o rendimento e o espaço disponível para a instalação, são também aspectos a ter em conta aquando da escolha dos painéis fotovoltaicos a instalar.

Outro aspecto importante na escolha dos painéis fotovoltaicos, são as perdas por efeito de "mismatch". Estas perdas são causadas pela interligação entre as células solares ou entre os painéis que não possuem características iguais, ou estão sujeitas(os) a condições diferentes. Estas perdas são um sério problema nos painéis fotovoltaicos pois, a saída deste vai ser limitada pela célula ou células com as condições mais desfavoráveis.

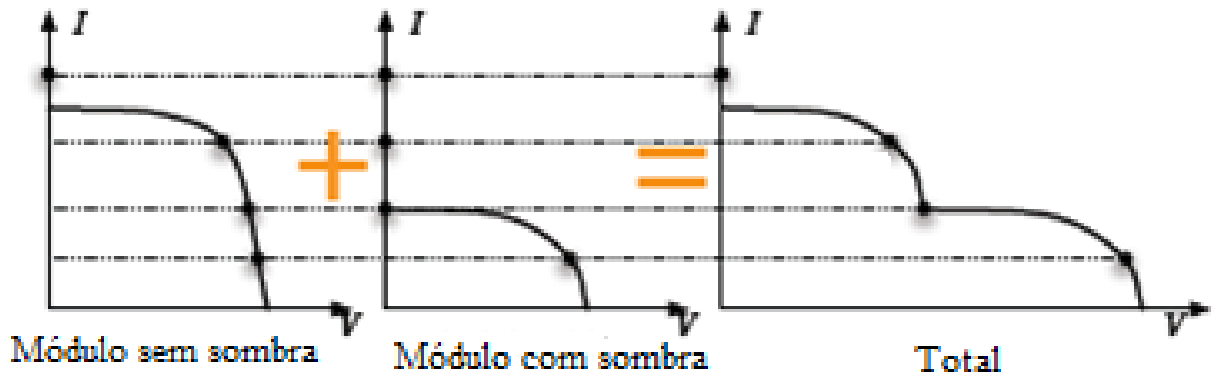

Fig. 6 - Efeito do sombreamento nos sistemas fotovoltaicos. 


\section{ARTIGO TÉCNICO}

Este fenómeno também acontece na interligação entre painéis, sendo a série de painéis limitada em corrente pelo painel que tem menor valor de corrente e em tensão pelo menor valor de tensão das "strings" ligadas em paralelo.

Por exemplo quando um painel de uma "string" está coberto por sombras, o valor da corrente da série de painéis em que este está colocado vai ser limitado pela corrente deste, logo fica limitada a potência da série.

Desta forma a potência superior produzida pelos painéis não atingidos pelo sombreamento tem de ser dissipada o que leva a que existam locais nos painéis em que a dissipação de potência provoca aquecimento que pode danificar irreversivelmente um painel.

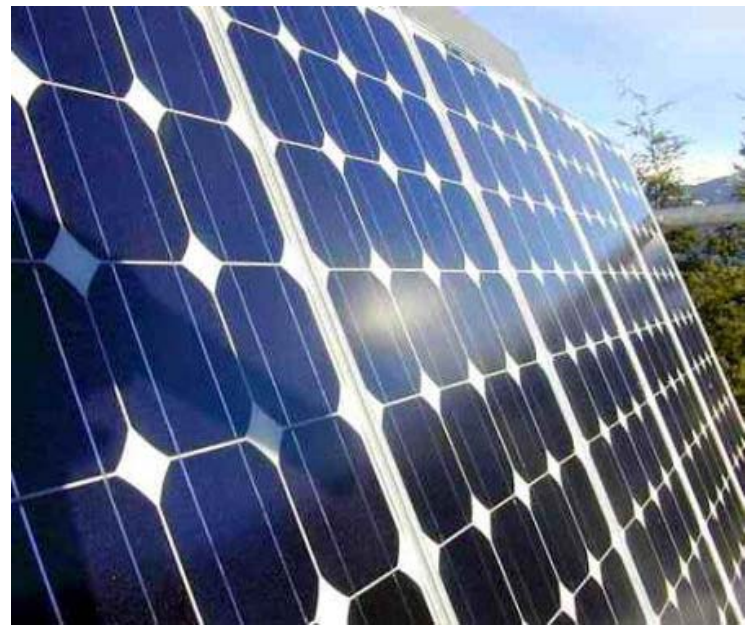

Fig. 7 - Sombreamento de painéis

\section{d) Estrutura de Suporte}

As estruturas de suporte são fundamentais para a instalação de uma central fotovoltaica, exigindo algum cuidado na escolha de entre as diversas variedades disponíveis no mercado.

Uma análise cuidada ao local de instalação da central para aferir se o terreno é regular ou irregular, ou no caso de ser para instalação em telhado se ele é inclinado ou não, é essencial para o correcto dimensionamento da estrutura de suporte.
Um outro aspecto importante, no caso de instalação em telhados é o peso do sistema. É preciso garantir que o peso da estrutura, painéis e inversor não causem colapso da estrutura do edifício.

Se a opção da central passar pela instalação de seguidores solares, para movimentação mono axial ou bi axial, a estrutura de suporte terá que ser dimensionada para permitir a instalação dos motores necessários à realização das deslocações. Embora haja estudos que garantam ganhos de produção na ordem dos $25 \%$ com a instalação de sistemas dotados de seguidores solares, questões como o aumento da manutenção do sistema terão que ser ponderadas.

A resistência aos ventos é também uma característica a ter em conta no dimensionamento da estrutura de suporte. Normalmente as estruturas são dimensionadas para suportar ventos até $150 \mathrm{Km} / \mathrm{h}$ e por isso nenhum dos apoios da estrutura de suporte deverá ter menos de $10 \mathrm{~cm}^{2}$ de superfície.

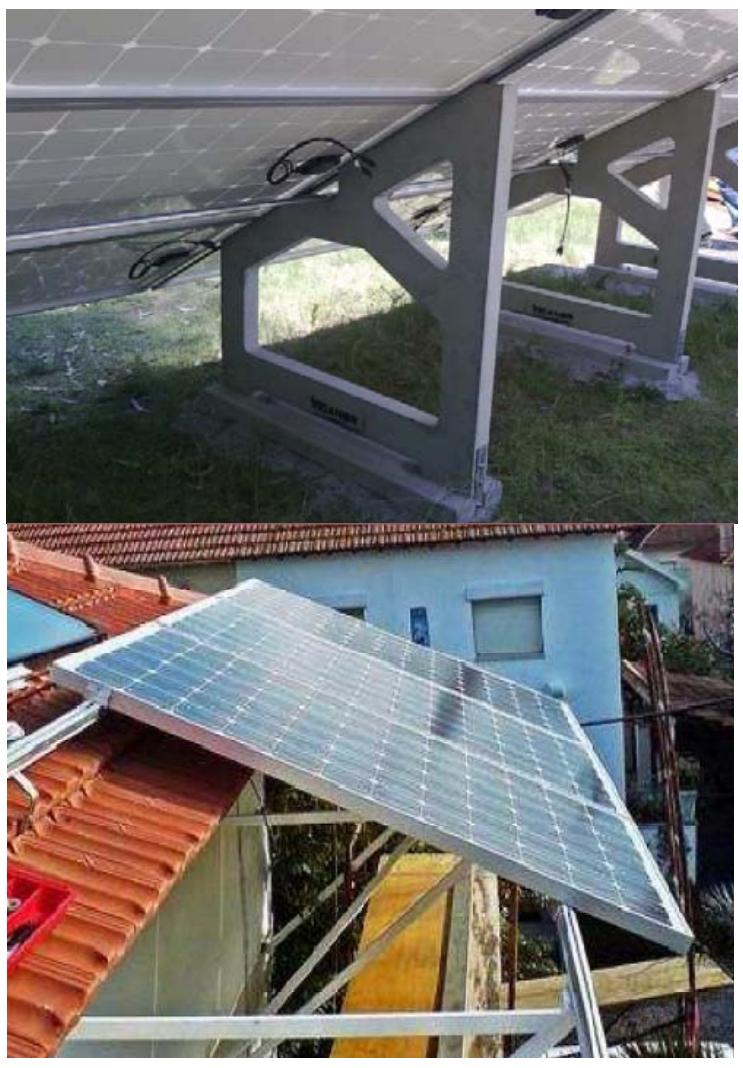

Fig. 8- Exemplos de estruturas de suporte 


\section{e) Potência DC Vs Potência AC}

Os painéis fotovoltaicos são caracterizados pela sua potência nominal máxima.

Essa potência, que obrigatoriamente deve constar na ficha técnica do produto, é obtida em condições STC (Standard Test Conditions), ou seja, com uma radiação de $1000 \mathrm{~W} / \mathrm{m}^{2}$, $25^{\circ} \mathrm{C}$ e $\mathrm{AM}=1,5$.

Como essas condições quase nunca não se verificam em condições reais de instalação e como existem perdas nos equipamentos, é aceitável fazer-se um sobredimensionamento da potência instalada por forma a se ter disponível na saída a máxima potência permitida para a instalação.

Em instalações reais é normal sobredimensionar-se o número de painéis a instalar, como forma de compensar este efeito.

No entanto, é preciso ter algum cuidado com o sobredimensionamento por forma a não se ultrapassar a máxima potência permitida à entrada do inversor.

\section{f) Simulação}

A simulação do sistema dimensionado e a análise dos relatórios produzidos pelo simulador deverão assumir importância crucial pois, é possível inferir daí informações sobre a viabilidade técnica e económica do projecto.

Existem inúmeros simuladores disponibilizados no mercado, uns em versão freeware, outros em que é necessária licença de instalação e utilização.

Um dos programas mais completos é o PVSyst [4]. Desenvolvido pelo Institut of Environmental Sciences da Universidade de Genebra, este software permite o estudo, dimensionamento, simulação e análise de dados de projectos fotovoltaicos.
Com este software é possível simular o funcionamento da central e aferir qual o melhor posicionamento dos painéis por forma a minimizar o efeito do sombreamento e a maximizar a energia produzida.
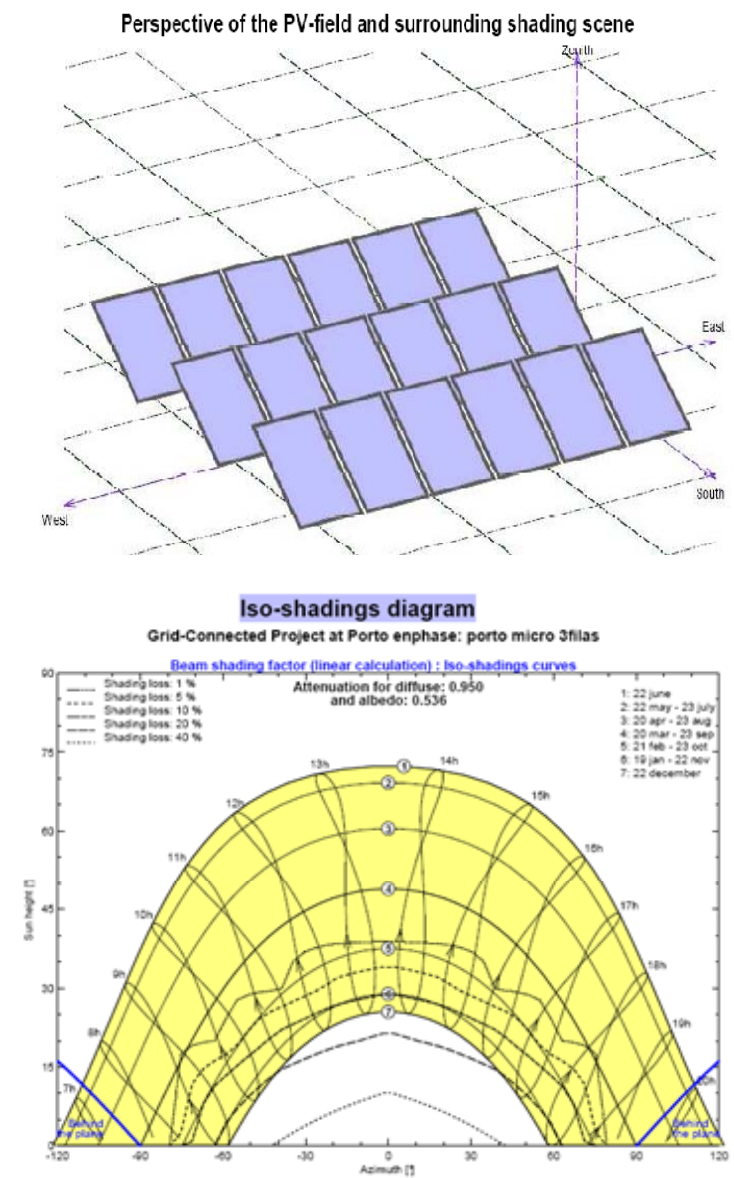

Fig.9 - Exemplo de dados obtidos do simulador

Informação sobre a energia prevista ser produzida e sobre as perdas do sistema, são também informações muito importantes de analisar porque são informações válidas para o cálculo dos indicadores de viabilidade económica do projecto em estudo.

Um outro indicador importante dado pelo software é o Performance Ratio (PR) do sistema fotovoltaico. Este indicador dá informação sobre a relação de energia efectivamente produzida pelo sistema e a energia que seria produzida por um sistema "ideal", a trabalhar nas condições STC. De salientar que sistemas com PR superiores a $70 \%$ podem já ser considerados eficientes. 


\section{ARTIGO TÉCNICO}

Normalmente este tipo de softwares disponibiliza uma base de dados muito completa sobre as condições meteorológicas dos diversos locais do planeta e possui informação sobre as características dos componentes dos inúmeros fabricantes existentes no mercado.

A qualidade e fiabilidade dos resultados obtidos pela simulação tornam esta ferramenta indispensável no dimensionamento deste tipo de sistemas.

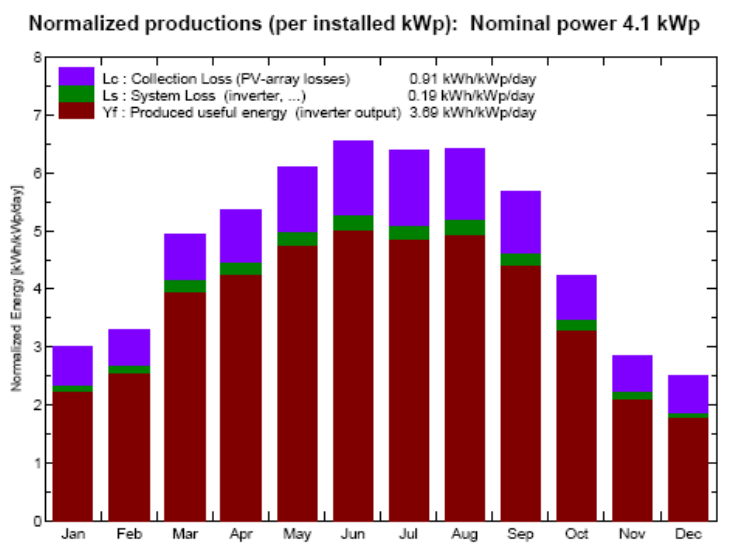

Fig. 10 - Energia produzida/ perdas mensais

\section{CONCLUSÕES}

Dado o recente aumento de instalações de microprodução, nomeadamente de centrais fotovoltaicas, e a rápida evolução que se tem verificado nesta área obrigam a uma cada vez maior necessidade de formação dos projectistas, comercializadores e instaladores deste tipo de sistemas de produção de energia.

Neste artigo foram abordados os aspectos aos quais se deve dar atenção aquando do dimensionamento de centrais fotovoltaicas.

Dada a necessidade de se projectar e instalar estes sistemas com a máxima rapidez, alguns dos assuntos aqui abordados são descurados na prática. No entanto, ficou provada a necessidade de um estudo cuidado de todos os componentes do sistema pois só assim se consegue obter o máximo proveito das instalações.

\section{REFERÊNCIAS}

[1] REN, Dados Técnicos Electricidade, Valores provisórios 2008

[2] WAED, www.localpower.org

[3] Burger, Bruno, "Auslegung und Dimensionierung von Wechselrichtern für netzgekoppelte PV-Anlagen", ISE, www.ise.fraunhofer.de

[4] PVsyst, www.pvsyst.com

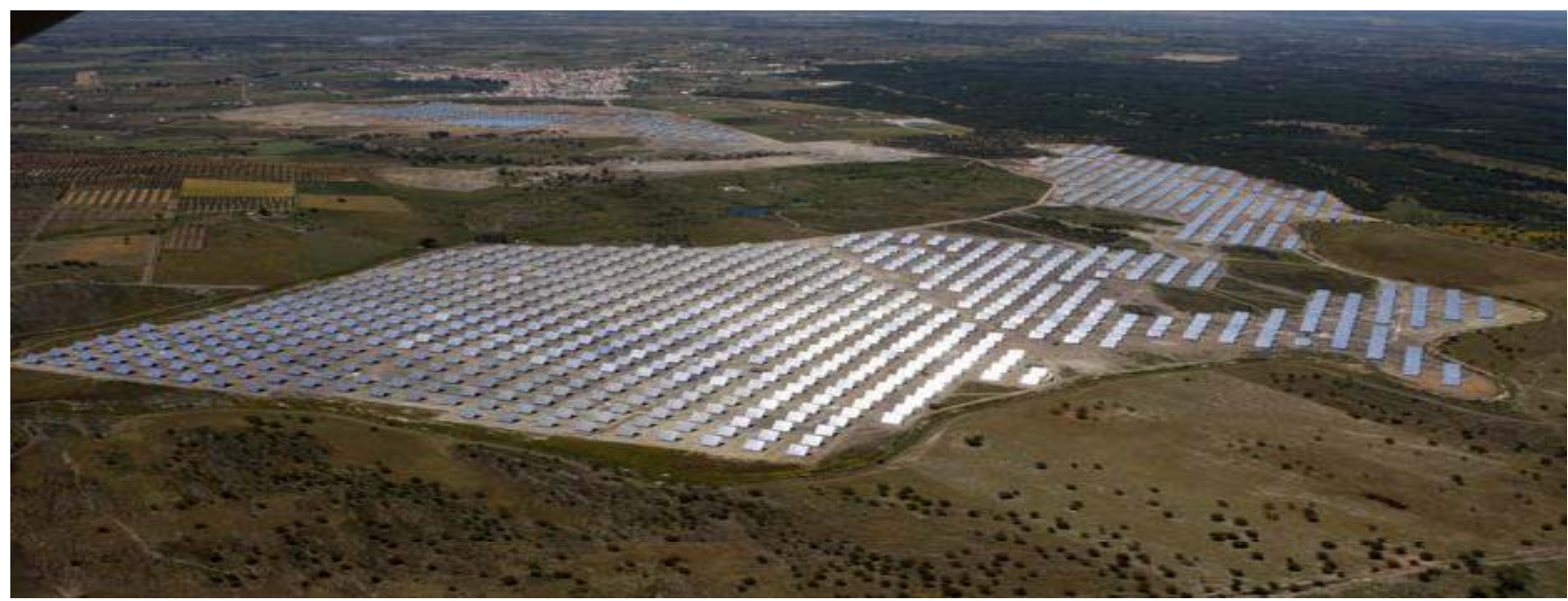

